\title{
Analysis of miR-148b expression differences in stage-I and II parosteal osteosarcoma
}

\author{
WENJUN LIN ${ }^{1}$, LU WANG ${ }^{1}$, SHENGWU YANG $^{1},{\text { XIN } \text { CHEN }^{1}, \text { XIONGBAI ZHU }^{1} \text { and PIJI CHEN }}^{2}$ \\ ${ }^{1}$ Department of Orthopedic Surgery, The First Affiliated Hospital of Wenzhou Medical University, \\ Wenzhou, Zhejiang 325000; ${ }^{2}$ BGI Shenzhen, Shenzhen, Guangdong 518000, P.R. China
}

Received October 4, 2017; Accepted May 8, 2018

DOI: $10.3892 /$ ol.2018.8709

\begin{abstract}
Expression of human serum albumin-micro RNA miR-148b in patients with stage-I and II parosteal osteosarcoma and its effect on prognosis were investigated. A total of 47 cases of fresh tissues of stage-I and II parosteal osteosarcoma and the corresponding para-carcinoma normal bone tissues resected by operation were collected; the expression of miR-148b in parosteal osteosarcoma tissues and normal bone tissues was detected, and the correlations of miR-148b expression in parosteal osteosarcoma tissues with clinicopathological parameters and prognosis were analyzed. The expression level of miR-148b in parosteal osteosarcoma tissues was significantly lower than that in para-carcinoma normal tissues $(\mathrm{P}<0.05)$. It was found that the low expression of miR-148b was correlated with the lung metastasis $(\mathrm{P}<0.05)$. Moreover, Kaplan-Meier survival curve analysis showed that the overall survival rate of patients in the low-expression miR-148b group was lower than that in the high-expression group $(\mathrm{P}<0.05)$. Multivariate Cox regression analysis revealed that the miR-148b level $(\mathrm{P}=0.003)$ was an independent prognostic factor affecting the prognosis. The results of this study showed that the expression of miR-148b in stage-I and II parosteal osteosarcoma tissues declines, which is related to the poor clinical prognosis of parosteal osteosarcoma.
\end{abstract}

\section{Introduction}

Parosteal osteosarcoma is a kind of malignant tumor with a low malignant degree and good differentiation, accounting for $3-5 \%$ of malignant tumors (1). Parosteal osteosarcoma often

Correspondence to: Dr Xiongbai Zhu, Department of Orthopedic Surgery, The First Affiliated Hospital of Wenzhou Medical University, Nan Bai Xiang Street, Ouhai, Wenzhou, Zhejiang 325000, P.R. China

E-mail: zhuxiongbai2016@163.com

Dr Piji Chen, BGI Shenzhen, Building 11, Beishan Industrial Zone, Yantian, Shenzhen, Guangdong 518000, P.R. China

E-mail: clf0pa@163.com

Key words: parosteal osteosarcoma, miR-148b, RT-qPCR, prognosis, 5-year survival rate occurs in the distal humerus, mostly manifested as a painless mass; it is very similar to the benign bone tumor, so both tumors are prone to misdiagnosis clinically (2).

At present, there are no special precautionary measures for parosteal osteosarcoma, and its treatment is also dominated by surgical resection, supplemented by chemotherapy. hsamir-148b is located on the human autosomal 12q13.13 and its expression is low in many human tumor tissues. Studies have shown that (3), miR-148b plays a role as a negative regulator of DNMT3B expression by inhibiting intracellular DNA methylation. Other studies have shown that (4) highly expressed miR-148b inhibits the proliferation and tumorigenesis of hepatoblastoma HepG2, and induces cell apoptosis through caspase-3 and caspase-9. miR-148b also regulates cyclin D1 and p21 to induce S-phase arrest and inhibits the invasion of hepatoblastoma. Therefore, it can be inferred from the above that miR-148b expression may reverse tumor progression to some extent. Currently, there are few studies on human serum albumin-micro RNA miR-148b in parosteal osteosarcoma, but there are many studies in breast cancer (5), hepatocellular carcinoma (6), lung cancer (7) and colorectal cancer (8).

In this study, the expression differences of miR-148b in stage-I and II parosteal osteosarcoma were detected and its effects on development of parosteal osteosarcoma were investigated.

\section{Materials and methods}

Specimen collection. A total of 47 cases of fresh tissues of stage-I and II parosteal osteosarcoma and the corresponding para-carcinoma normal bone tissues resected by operation (stored in liquid nitrogen within $10 \mathrm{~min}$ ) in The First Affiliated Hospital of Wenzhou Medical University from 2007 to 2012 were collected. All patients were diagnosed with parosteal osteosarcoma in Pathology Department in the hospital, including 27 males and 20 females aged 20.5 \pm 8.1 years. In terms of Enneking staging, there were 20 cases in stage I, 15 cases in stage IIA, 9 cases in stage IIB and 3 cases in stage III. All the patients in this experimental study were followed up. This study was approved by the Ethics Committee of The First Affiliated Hospital of Wenzhou Medical University, and the patients or their families signed the informed consent.

Major reagents and instruments. Reverse transcriptase and reverse transcription kit were purchased from Takara 
Biotechnology Co., Ltd. (Beijing, China); $2 \times$ synergy brands (SYBR) Green quantitative polymerase chain reaction (qPCR) mix and RevertAid first strand complementary DNA (cDNA) synthesis kit were both purchased from Invitrogen (Thermo Fisher Scientific, Inc., Waltham, MA, USA); 7900HT fluorescence qPCR instrument was purchased from Applied Biosystems (Thermo Fisher Scientific, Inc.); primers were synthesized by Sangon Biotech Co., Ltd. (Shanghai, China).

\section{RNA extraction and $R T-q P C R$}

$R N A$ extraction. Parosteal osteosarcoma tissues and normal para-carcinoma tissues were ground and added with the lysis buffer. The total RNA was extracted by using the TRIzol reagent, and the concentration and purity of RNA extracted were detected by using the ultraviolet spectrophotometer. RNAs with the optical density (OD)260/OD280 ratio between 1.8 and 2.1 were reverse transcribed into cDNA. Reaction conditions are as follows: $72^{\circ} \mathrm{C}$ for $3 \mathrm{~min}, 42^{\circ} \mathrm{C}$ for $60 \mathrm{~min}$, and $95^{\circ} \mathrm{C}$ for $3 \mathrm{~min}$. The synthesized cDNA reaction solution was stored at $-20^{\circ} \mathrm{C}$.

Reverse transcription $(R T)-q P C R$. RT-qPCR was performed by using miScript SYBR-Green PCR kit, and the reaction system was prepared according to the instructions. miR-148b: forward primer: 5'-CCAAATTTCCCAATCAGG CATCACAG-3'; reverse primer: 5'-TAACCATTAGCAGGGT CCGAGGTATTC-3'. Reaction conditions are as follows: pre-denaturation at $95^{\circ} \mathrm{C}$ for $10 \mathrm{~min} ; 95^{\circ} \mathrm{C}$ for $15 \mathrm{sec}, 60^{\circ} \mathrm{C}$ for $30 \mathrm{sec}$ and $72^{\circ} \mathrm{C}$ for $15 \mathrm{sec}$, a total of 45 cycles. Glyceraldehyde-3-phosphate dehydrogenase (GAPDH) was used as the internal reference, and the relative expression level of miR-148b was calculated by using $2^{-\Delta \Delta \mathrm{Cq}}$.

Statistical analysis. In this study, Statistical Product and Service Solutions (SPSS) 17.0 software package (SPSS Inc., Chicago, IL, USA) was used for data processing and statistical analysis. Measurement data are presented as mean \pm standard deviation. The Chi-square test was used for enumeration data, Student's t-test was used for the measurement data between groups, and analysis of variance was used for the measurement data among groups. Kaplan-Meier analysis was used for survival analysis and log-rank test for comparison of survival rate between the two groups. Cox regression analysis was used for the univariate analysis of survival data. $\mathrm{P}<0.05$ was considered to indicate a statistically significant difference.

\section{Results}

miR-148b expression in parosteal osteosarcoma tissues and para-carcinoma normal tissues. The detection of 47 cases of parosteal osteosarcoma tissues via RT-qPCR showed that the relative expression level of miR-148b in parosteal osteosarcoma tissues was significantly lower than that in paracarcinoma normal tissues, and the difference was statistically significant $(\mathrm{P}<0.05)$ (Fig. 1).

Correlation analysis of clinical factors of parosteal osteosarcoma and miR-148b expression. According to the median value obtained in the experiment, patients with parosteal osteosarcoma were divided into the high-expression group $(n=22)$ and the low-expression group $(n=25)$. The

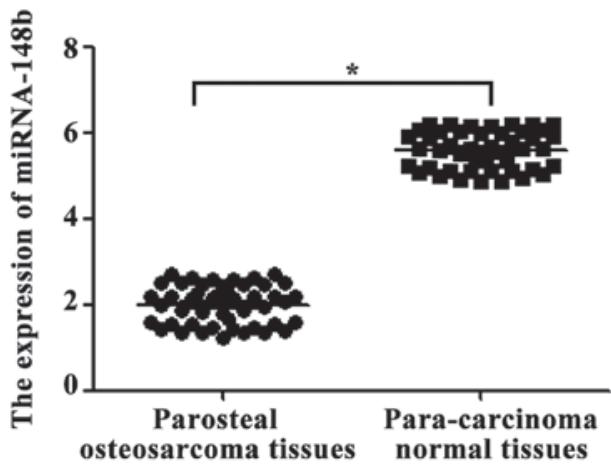

Figure 1. Expression of miRNA-148b in parosteal osteosarcoma tissues and para-carcinoma normal tissues; compared with that in para-carcinoma normal tissues, the expression of miRNA-148b in parosteal osteosarcoma tissues is significantly lower $\left({ }^{*} \mathrm{P}<0.05\right)$.

Table I. Correlation analysis of clinical factors of parosteal osteosarcoma and hsa-miR-148b expression.

\begin{tabular}{|c|c|c|c|c|c|}
\hline $\begin{array}{l}\text { Clinical } \\
\text { factor }\end{array}$ & $\mathrm{n}$ & $\begin{array}{l}\text { Low-expression } \\
\text { hsa-miR-148b }\end{array}$ & $\begin{array}{l}\text { High-expression } \\
\text { hsa-miR-148b }\end{array}$ & $\chi^{2}$ & P-value \\
\hline Sex & & & & 0.094 & 0.784 \\
\hline Male & 27 & 17 & 10 & & \\
\hline Female & 20 & 8 & 12 & & \\
\hline Age & & & & 0.574 & 0.614 \\
\hline$\geq 30$ & 21 & 13 & 8 & & \\
\hline$<30$ & 26 & 12 & 14 & & \\
\hline Tumor size & & & & 0.841 & 0.517 \\
\hline$>5 \mathrm{~cm}$ & 17 & 10 & 7 & & \\
\hline$\leq 5 \mathrm{~cm}$ & 30 & 15 & 15 & & \\
\hline $\begin{array}{l}\text { Enneking } \\
\text { staging }\end{array}$ & & & & 0.874 & 0.769 \\
\hline Stage I & 20 & 12 & 8 & & \\
\hline Stage II & 24 & 11 & 13 & & \\
\hline Stage III & 3 & 2 & 1 & & \\
\hline Pathological & & & & 0.414 & 0.376 \\
\hline Osteoblast & 21 & 10 & 11 & & \\
\hline Chondrocyte & 14 & 8 & 6 & & \\
\hline Fibroblast & 7 & 4 & 3 & & \\
\hline Others & 5 & 3 & 2 & & \\
\hline Chemotherapy & & & & 0.494 & 0.582 \\
\hline Yes & 27 & 15 & 12 & & \\
\hline No & 20 & 10 & 10 & & \\
\hline $\begin{array}{l}\text { Smoking } \\
\text { history }\end{array}$ & & & & 0.541 & 0.618 \\
\hline Yes & 27 & 17 & 10 & & \\
\hline No & 20 & 10 & 10 & & \\
\hline $\begin{array}{l}\text { Lung } \\
\text { metastasis }\end{array}$ & & & & 3.574 & 0.014 \\
\hline Yes & 35 & 20 & 15 & & \\
\hline No & 12 & 5 & 7 & & \\
\hline
\end{tabular}

statistical analysis showed that the low expression of miR-148b was not correlated with the sex, age, Enneking staging, chemotherapy, smoking history, tumor size and pathological 


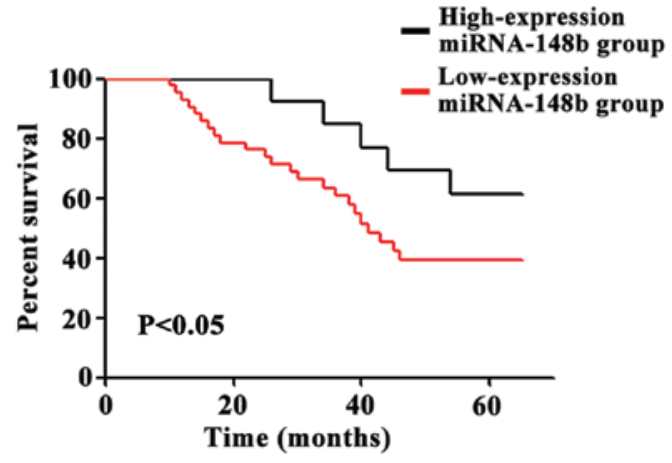

Figure 2. Kaplan-Meier survival curves of high- and low-expression miRNA-148b groups; the survival rate in the high-expression group is significantly higher than that in the low-expression group $(\mathrm{P}<0.05)$.

type $(\mathrm{P}>0.05)$, but was correlated with the lung metastasis $(\mathrm{P}<0.05)$ (Table I).

Kaplan-Meier survival analysis. Forty-seven patients were followed up for 72 months. Five out of 22 patients with parosteal osteosarcoma in high-expression group died, and the 5-year survival rate was $77.2 \%$. Nineteen out of 25 patients with parosteal osteosarcoma in the low-expression group died, and the 5 -year survival rate was $40 \%$. As shown in Fig. 2 the survival time of patients in the high-expression group was significantly longer than that of patients in the low-expression group, and the difference was statistically significant $(\mathrm{P}<0.05)$ (Fig. 2).

Cox regression analysis. Finally, all clinical data were collected and analyzed by univariate Cox regression, and the factors with $\mathrm{P}<0.05$ were analyzed by multivariate Cox regression. The results of univariate Cox regression analysis showed that the factors had no correlation with patients' sex, age, tumor size, chemotherapy, smoking history and Enneking stage $(\mathrm{P}>0.05)$, but had correlations with the pathological type, lung metastasis and low-expression miR-148b in patients $(\mathrm{P}<0.05)$. The multivariate Cox regression analysis revealed that the low expression of miR-148b was an independent factor affecting the prognosis of patients with parosteal osteosarcoma $(\mathrm{P}<0.05)($ Table II).

\section{Discussion}

At present, parosteal osteosarcoma mainly exists in adolescents and children, and is one of the bone tumors with a high malignant grade and strong capacity for invasion and proliferation $(9,10)$. It often occurs in distal humerus, and its early symptoms are swelling and pain and it is not easily detectable; if there is no appropriate treatment, patients are prone to lung metastasis, thus leading to poor prognosis (11).

miRNA is a non-coding small-molecule single-stranded RNA that is highly conserved in the body, and increasing evidence in the literature world-wide shows that miRNAs are involved in tumor migration, invasion and proliferation, and cell regulation capacity (12). It has been reported (13) that the miRNA expression is different in parosteal osteosarcoma tissues; some miRNAs are upregulated, while some are downregulated, which may play a certain regulating role in the occurrence and development of tumors (14). miR-148b is expressed in a variety of tumors, such as nasopharyngeal carcinoma (15), liver cancer (16) and lung cancer (17). However, there are not many studies on miR-148b in parosteal osteosarcoma. In this study, the correlation analysis was performed for the expression of miR-148b in patients with parosteal osteosarcoma for the first time, so as to provide new targets and scientific basis for the treatment of parosteal osteosarcoma.

The results of this study showed that the expression of miR-148b had a statistically significant difference in parosteal osteosarcoma tissues and para-carcinoma normal tissues. Ge et al (18) reported that the miR-148b is downregulated in lung cancer tissues, suggesting that there may be a certain relationship between them. It was found via correlation analysis that the low expression of miR-148b was not related to the patients' sex, age, Enneking staging, chemotherapy, smoking history, tumor size or pathological type ( $>0.05)$, but related to the lung metastasis $(\mathrm{P}>0.05)$. Finally, Cox regression analysis was performed for the data collected. The univariate Cox regression analysis revealed that the pathological type, lung metastasis

Table II. Cox regression analysis of miR-148b and clinical factors in the prognosis of patients with parosteal osteosarcoma.

\begin{tabular}{|c|c|c|c|c|c|c|c|c|}
\hline \multirow[t]{2}{*}{ Pathological characteristic } & \multicolumn{4}{|c|}{ Univariate Cox } & \multicolumn{4}{|c|}{ Multivariate Cox } \\
\hline & $\mathrm{HR}$ & $95 \% \mathrm{CI}$ & $\chi^{2}$ & P-value & HR & $95 \% \mathrm{CI}$ & $\chi^{2}$ & P-value \\
\hline Sex & 1.841 & $0.677-2.984$ & 0.874 & 0.415 & & & & \\
\hline Age & 1.417 & $0.874-3.541$ & 0.687 & 0.533 & & & & \\
\hline Tumor size & 0.874 & $0.438-1.874$ & 1.341 & 0.474 & & & & \\
\hline Enneking staging & 0.611 & $0.398-1.341$ & 3.568 & 0.749 & & & & \\
\hline Pathological type & 3.841 & $1.984-4.984$ & 7.543 & 0.017 & 2.341 & $1.094-3.846$ & 0.679 & 0.084 \\
\hline Chemotherapy & 0.984 & $0.684-2.165$ & 1.267 & 0.081 & & & & \\
\hline Smoking history & 0.688 & $0.384-1.488$ & 0.987 & 0.384 & & & & \\
\hline Lung metastasis & 3.412 & $1.974-5.847$ & 7.151 & 0.024 & & & & \\
\hline miRNA-158b expression & 4.974 & $1.974-11.541$ & 8.984 & 0.001 & 4.869 & $1.533-13.846$ & 1.467 & 0.003 \\
\hline
\end{tabular}

HR, hazard ratio; CI, confidence interval. 
and low-expression miR-148b were the prognostic factors, while the multivariate Cox regression analysis showed that the low-expression miR-148b was an independent factor affecting the prognosis of patients with parosteal osteosarcoma, which further suggested that the low-expression of miR-148b is one of the key factors affecting the clinicobiological behavior of parosteal osteosarcoma, and the low-expression of miR-148b plays a role in the occurrence, development and prognosis of parosteal osteosarcoma; furthermore, the low-expression hsa-miR-148b can be used as an effective prognostic index for patients with parosteal osteosarcoma. In recent years, the treatment level of parosteal osteosarcoma has improved, and the survival rates after different therapeutic regimens have also increased, but drug resistance generally occurs in the late stage of treatment, and the risk for recurrence and metastasis is high $(19,20)$.

There were also shortcomings in this study: the patients were from one city, so the samples were not representative because of the lack of geographical differences; besides, the small sample size might produce biased results. This study is a clinical study, and the mechanism of the role of miR-148b was not investigated. It can only be speculated that downregulation of miR-148b may lead to the activation or inactivation of its downstream target genes so that the development of cancer can be promoted. In future studies, the number of samples will be increased and in-depth investigations on the downstream pathways and target genes of miR-148b will be performed to support the results of this study.

In conclusion, the expression of miR-148b in parosteal osteosarcoma tissues and para-carcinoma normal tissues and the clinical factors were detected via RT-qPCR in this study for the first time. It was found that the expression of miR-148b was low in patients with parosteal osteosarcoma, and miR-148b was related to the lung metastasis in patients. Moreover, it was found via Kaplan-Meier survival analysis that the survival time in the low-expression group was significantly shorter than that in the high-expression group. These results suggest that the differential expression of miR-148b can be used as a potential biological index of parosteal osteosarcoma.

\section{Acknowledgements}

Not applicable.

\section{Funding}

No funding was received.

\section{Availability of data and materials}

The datasets used and/or analyzed during the present study are available from the corresponding author on reasonable request.

\section{Authors' contributions}

WL, LW and XZ conceived and designed the study. WL, SY, $\mathrm{XC}$ and $\mathrm{PC}$ were responsible for the collection and analysis of the patient data. $\mathrm{LW}$ and $\mathrm{XZ}$ interpreted the data and drafted the manuscript. WL and PC revised the manuscript critically for important intellectual content. All authors read and approved the final study.

\section{Ethics approval and consent to participate}

The study was approved by the Ethics Committee of The First Affiliated Hospital of Wenzhou Medical University. Signed informed consents were obtained from the patients or the guardians.

\section{Consent for publication}

Not applicable.

\section{Competing interests}

The authors declare that they have no competing interests.

\section{References}

1. Isakoff MS, Bielack SS, Meltzer P and Gorlick R: Osteosarcoma: Current treatment and a collaborative pathway to success. J Clin Oncol 33: 3029-3035, 2015.

2. Luetke A, Meyers PA, Lewis I and Juergens H: Osteosarcoma treatment - where do we stand? A state of the art review. Cancer Treat Rev 40: 523-532, 2014.

3. Azizi M, Teimoori-Toolabi L, Arzanani MK, Azadmanesh K, Fard-Esfahani P and Zeinali S: MicroRNA-148b and microRNA-152 reactivate tumor suppressor genes through suppression of DNA methyltransferase-1 gene in pancreatic cancer cell lines. Cancer Biol Ther 15: 419-427, 2014.

4. Zhang JG, Shi Y, Hong DF, Song M, Huang D, Wang CY and Zhao G: MiR-148b suppresses cell proliferation and invasion in hepatocellular carcinoma by targeting WNT1/ $\beta$-catenin pathway. Sci Rep 5: 8087, 2015.

5. Borel F, Konstantinova P and Jansen PL: Diagnostic and therapeutic potential of miRNA signatures in patients with hepatocellular carcinoma. J Hepatol 56: 1371-1383, 2012.

6. Liu Q, Xu Y, Wei S, Gao W, Chen L, Zhou T, Wang Z, Ying M and Zheng Q: miRNA-148b suppresses hepatic cancer stem cell by targeting neuropilin-1. Biosci Rep 35: e00229, 2015.

7. Yang JS and Li BJ, Lu HW, Chen Y, Lu C, Zhu RX, Liu SH, Yi QT, Li J and Song CH: Serum miR-152, miR-148a, miR-148b, and miR-21 as novel biomarkers in non-small cell lung cancer screening. Tumour Biol 36: 3035-3042, 2015.

8. Li T, Yin J, Yuan L, Wang S, Yang L, Du X and Lu J: Downregulation of microRNA-139 is associated with hepatocellular carcinoma risk and short-term survival. Oncol Rep 31: 1699-1706, 2014.

9. Chen X, Bahrami A, Pappo A, Easton J, Dalton J, Hedlund E, Ellison D, Shurtleff S, Wu G, Wei L, et al; St. Jude Children's Research Hospital-Washington University Pediatric Cancer Genome Project: Recurrent somatic structural variations contribute to tumorigenesis in pediatric osteosarcoma. Cell Rep 7: 104-112, 2014.

10. Cheng D, Qiu X, Zhuang M,Zhu C, Zou H and Liu Z: MicroRNAs with prognostic significance in osteosarcoma: A systemic review and meta-analysis. Oncotarget 8: 81062-81074, 2017.

11. Wang Z, Cai H, Lin L, Tang M and Cai H: Upregulated expression of microRNA-214 is linked to tumor progression and adverse prognosis in pediatric osteosarcoma. Pediatr Blood Cancer 61: 206-210, 2014.

12. Wu X, Zhong D, Gao Q, Zhai W, Ding Z and Wu J: MicroRNA-34a inhibits human osteosarcoma proliferation by downregulating ether à go-go 1 expression. Int J Med Sci 10: 676-682, 2013.

13. Cote GA, Gore AJ, McElyea SD, Heathers LE, Xu H, Sherman S and Korc M: A pilot study to develop a diagnostic test for pancreatic ductal adenocarcinoma based on differential expression of select miRNA in plasma and bile. Am J Gastroenterol 109: 1942-1952, 2014.

14. Dahlmans D, Houzelle A, Schrauwen $\mathrm{P}$ and Hoeks J: Mitochondrial dynamics, quality control and miRNA regulation in skeletal muscle: Implications for obesity and related metabolic disease. Clin Sci (Lond) 130: 843-852, 2016.

15. Wu M, Ye X, Wang S, Li Q, Lai Y and Yi Y: MicroRNA-148b suppresses proliferation, migration, and invasion of nasopharyngeal carcinoma cells by targeting metastasis-associated gene 2. OncoTargets Ther 10: 2815-2822, 2017. 
16. Drakaki A, Hatziapostolou M, Polytarchou C, Vorvis C, Poultsides GA, Souglakos J, Georgoulias V and Iliopoulos D: Functional microRNA high throughput screening reveals miR-9 as a central regulator of liver oncogenesis by affecting the PPARA-CDH1 pathway. BMC Cancer 15: 542, 2015.

17. Yang JS, Li BJ, Lu HW, Chen Y, Lu C, Zhu RX, Liu SH, Yi QT, Li J and Song CH: Serum miR-152, miR-148a, miR-148b, and miR-21 as novel biomarkers in non-small cell lung cancer screening. Tumour Biol 36: 3035-3042, 2015.

18. Ge H, Li B, Hu WX, Li RJ, Jin H, Gao MM and Ding CM: MicroRNA-148b is down-regulated in non-small cell lung cancer and associated with poor survival. Int J Clin Exp Pathol 8: $800-805,2015$
19. Josefsson A, Hobbs R, Mauxion T, Frey E, Terezakis S, Meyer C, Loeb D and Sgouros G: Combined treatment planning and therapy using 153Sm-EDTMP RPT with XRT in pediatric metastatic osteosarcoma patients. J Nucl Med 56: 341, 2015.

20. Xu YF, Jiang SJ, Wang YQ, Yao YW and Liu YX: A survival analysis and treatment outcomes of 131 cases of osteosarcoma treated with high-dose methotrexate multidrug chemotherapy. Int J Clin Exp Med 9: 8465-8473, 2016. Attribution-NonCommercial-NoDerivatives 4.0 International (CC BY-NC-ND 4.0) License. 